\title{
The Teaching Profession Amid Changes in the Educational Ecosystems
}

\author{
Niemi, Hannele
}

Brill Sense

2018

Niemi , H , Toom , A , Kallioniemi , A \& Lavonen , J 2018 , The Teaching Profession Amid Changes in the Educational Ecosystems . in H Niemi , A Toom , A Kallioniemi \& J Lavonen (eds), The Teacher's Role in the Changing Globalizing World : Resources and Challenges Related to the Professional Work of Teaching . Brill Sense, Leiden , pp. 141-149 . < https://brill.com/abstract/book/edcoll/9789004372573/BP000014.xml >

http://hdl.handle.net/10138/310378

unspecified

acceptedVersion

Downloaded from Helda, University of Helsinki institutional repository.

This is an electronic reprint of the original article.

This reprint may differ from the original in pagination and typographic detail.

Please cite the original version. 


\title{
10. THE TEACHING PROFESSION AMID CHANGES IN THE EDUCATIONAL ECOSYSTEMS
}

\author{
INTRODUCTION
}

\begin{abstract}
The chapters in this book provide strong evidence that the role of teacher is changing all over the world. Teachers are in a middle of societal and technological changes. The authors of the various chapters in this book look at the changes from different educational contexts and describe how teachers are expected to prepare the next generation of citizens to be able to live and work in a future that is unpredictable and requires continuous learning and new meta-skills in changing conditions. Many of the authors reflect in a similar fashion as Leijen and Pedaste in Estonia on the fact that the knowledge capital of citizens is the most important force driving knowledge economies. The political, social, and economic advancements of any country heavily depend on how well they develop and tap into the intellectual potential of their youth. We can see that in many countries the abilities of students is seen from the viewpoint of their future working lives, and educational systems strive through major reforms to prepare their students for occupations in the twenty-first century.
\end{abstract}

However, students in schools should be be viewed only members future workforces. Education is also needed for the students' own lives. The task of schools is also to provide them with competencies to manage their own learning and grow as active citizens. In most countries, schools curricula are being reformed towards supporting the learning of $21^{\text {st }}$ century skills (cf. Voogt \& Roblin, 2012; Griffin, Care \& McGaw, 2012). Lee and Tan state in their analysis of future skills that despite their varied emphases on frameworks of $21 \mathrm{st}^{\mathrm{s}}$ century skills definitions educators all mention some common skills, such as creativity, innovation, critical thinking, problem solving, communication skills, collaboration, information and digital literacy, conflict resolution, and social and inter-cultural skills. These skills are often given the following labels: $21 \mathrm{st}^{\mathrm{s}}$ century skills, competencies, core competences, transversal or generic skills. The new curriculum reforms have changed the way teachers are perceived. Teachers are expected to teach academic contents, but at the same time, they are now responsible for a whole host of wider, complex and often also multidisciplinary objectives. Consequently, education is important for the well-being of children of different ages. For example, it is known that quality education could have a strong impact on the reducing the numbers of unemployed young people the rates that they drop out of formal education (Berger \& Fisher, 2013). We may ask how teachers can meet these goals? What kinds of pedagogies are required to teach these skills and in which kinds of curricular conditions could these pedagogies be utilised.

In the chapters of this book, many themes related to the teachers' role and tasks are connected to the changing conceptions of the teaching profession. The questions of professional autonomy, teachers' voice in reforms, and teachers' pedagogical leadership in centralized or decentralized systems need urgent attention in most countries.

\section{TEACHERS' PROFESSIONAL AUTONOMY}

Autonomy is one of the most important features in high level professions, such as medicine or professions related to the law. It is also a key factor in the teaching profession, but the degree to which teachers have autonomy varies. In some countries like Finland teachers have autonomy to design local curriculums, choose learning materials and decide teaching and assessment methods. In many other countries teachers are more controlled by national standards, students' high-stake testing, and teachers' professional assessments.

Professional autonomy has many faces. Lavonen, referring to Goe's, Bell's, and Little' s (2008) conceptualization, claims that the professionalism and effectiveness of a teacher is typically approached through analyzing (a) the knowledge base of a professional teacher (the input approach), (b) the process or interaction that occurs in the classroom between the teacher and students (process approach), or (c) the outcomes of the teaching and learning process, such as students' learning outcomes measured by national tests or graduation rates (the output approach). The first one, the input approach mainly considers teachers' capacities to work as high-level professionals in schools. It often means high-level teacher education and support systems in schools to empower teachers in their work. The basis of autonomy is created already in pre-service teacher education (cf. Toom et al. 2017). The term "knowledge" is interpreted broadly in this context and is close to "competence" or "skill." This knowledge base supports the broad planning, organization, and evaluation of teachers' own instructional practices, student learning and learning outcomes. Broad planning encompasses the planning of local curriculums down to the planning of a single lesson. According to this input, professional teachers have a versatile knowledge base, allowing them to act as autonomous professionals. However, teacher autonomy does not only refer to an individual teacher and his/her competence to act autonomously but also to whole education context. In order for teachers to be autonomous school level factors and cultural and education policy factors should be supportive of this 
autonomy (Müller, Norrie, Hernández, \& Goodson, 2010). For example, the nature of leadership, quality work, collaboration culture and the structure of networks and school-society-family partnerships are important school level factors that could support teachers' autonomy. Moreover, cultural and education policy factors could support teacher autonomy and they include the state level education context, this includes considerations such is if the country follows a more accountability policy or it trusts teachers and does not rely on heavy inspection and testing.

Singapore has invested a lot on teacher education and they have excellent learning outcomes in their schools. Finland is also a country where teachers go through a high quality 5-year academic programme. However, even though Singapore and Finland seem to be similar in emphasizing high quality teacher education, there are major differences in their output evaluation methods. In Singapore, national tests and standards are also driving forces for getting high quality learning outcomes. The Finnish system is based on trust and teachers are supported to use their professional capacities in schools without testing or inspection. Sample-based assessments are utilized only for development purposes, and their results are never published publicly. Consequently, in different education contexts teacher autonomy and teacher control could influence the quality of students' learning outcomes. During their teacher education, teachers have to learn how and why the context and quality of work support or push teachers to implement high quality education. In the U.S., teachers have to cope with the intense pressures of a testing culture. the focus there being more on outputs than inputs.

Leijen and Pedaste, when examining the Estonian context raised the question of why the teaching profession does not seem more attractive and teachers' work is not more innovative. They came to the conclusion that one of the reasons might be that teachers' autonomy has not received sufficient support; therefore, the willingness of teacher's to adopt changes and their self-efficacy should be supported much more. They stress that the autonomies of schools and teachers autonomy should be strengthened in order to enhance teachers' positions and the attractiveness of the profession in society. They also claim that more resources are needed for teachers' continuous professional development. In the case of Malta, Bezzina claims that schools are becoming extremely demanding and complex environments. At the same time, teachers are faced with what Helterbran describes as "prescriptive, teacher-proof curricula and instructional strategies driven by politically mandated forces" $(2008,124)$, further augmented by top-down teacher accountability driven by standardized tests and external international testing. These demands and pressures have raised a clarion call to review how we conceptualize teacher professionlaism and the professional development of teachers. Bezzina argues for liberalizing professional learning so that school leaders and teachers could manage and control their own learning, even if they have to function in a context of restricted autonomy. This calls for a respect for teaching as a profession that allows space and time for teachers to engage in transformative learning from within.

In all countries examined, teachers are tied to national educational goals and aims, but there are big differences in the extent to which teachers are allowed to work as real professions. There are also big differences in how teachers learn to act in these kinds of roles already during their pre-service teacher education, and how they are supported in their role to work as independent professionals. This contradiction seems to grow if teachers are expected to work innovatively while developing teaching and learning in schools, but they lack the support and working conditions that are the critical features of a high-level professional community.

\section{HOW TEACHERS' VOICES ARE HEARD?}

Educational reforms are reality in all countries that have been described in the chapters of this book. There seem to exist big differences in how much teachers are involved and heard in the educational reform processes. The common problem in many countries is that reforms are top-down processes, and teachers feel that the innovations they produce were forced upon them. These kinds of experiences are known all around the globe. The Dutch authors, Wubbels and van Tartwijk describe a case where teachers' voices were neglected in the national education reform in the Netherlands. A parliamentary committee recommended afterwards that these kinds of reforms should never be implemented again without support from the educational field and, more specifically, from the teachers. The committee set up by the minister of education reported that teachers had not been sufficiently involved in the design of the reforms, with negative effects for the success of the innovations and the satisfaction of teachers with their jobs. This committee advocated a stronger position of the teachers, for example, by introducing a professional register for teachers and developing criteria for excellence in teaching.

What is the teachers' voice and in which ways could it be heard? It may also be difficult to be reached and heard. The Maltese author, Bezzina of the individualistic nature of the teaching profession. Teaching is a solitary profession with teachers who spend a considerable amount of time isolated in the classroom. Due to the characteristics of the work, teachers work independently in lonely circumstances, and it is difficult for them to articulate what they know and to share what they have learned through their own practices with others (Attard Tonna \& Calleja, 2015). He argues that the individualistic nature of teaching and the lack of a social dimension embedded within it precludes it from improving its efficiency and effectiveness through facilitated coordinated action (Putman, 1993). It would be necessary for teachers to 
come together to engage in a professional discourse, and so allow them to challenge the way they do things, thus helping each other to question actively, critically, and reflectively (Gordon, 2004).

In order to attain a high quality professional status in society, teachers should have the capacity to let their voices be heard in educational processes. This will not happen if teacher do not have opportunities to grow as professional experts. The Maltese studies have shown that while education is prized for its high value and social contribution, this is not matched with respect and prestige (Portelli, 2004). Teachers can react with anger, frustration and disengagement to reforms due to the growing demands of the teaching profession. Their reasons may be related to limited support (Borg \& Bugeja, 2015; Cutajar, 2015), but also to the teaching culture that has not allowed teachers to articulate their voice as professionals.

\section{CENTRALIZATION - DECENTRALIZATION OF EDUCATIONAL SYSTEMS}

Decentralization in education gives power to the local level. That is a typical feature in the Finnish educational system. Schools are responsible for the local curricula, which are designed by teachers and principals. Teachers have the freedom to choose which teaching and assessment methods they apply and what teaching and learning materials they use. The leading principle is that they make choices and decisions in line with the curricular goals that support various learners' growth in the best possible way (Halinen \& Järvinen, 2008). Collaborative planning is one part of the qulaity processes in Finnish schools. Moreover, the schools and teachers should be active in analysing the implementation based on different types of feedback.

Interestingly, decentralization does not automatically mean teachers' power or educational leadership. The American case described by LeTendre shows that decentralization can also become a significant barrier to teacher learning and professional development. The administration system at the local level can shift teachers' leadership to the school administration. The chapter from the U.S. context describes how the division between teachers and administrators can make teachers powerless. Within schools, this division of teaching and school administration professions creates a culture of managers (principals) and employees (teachers) that subordinates teachers' roles as leaders and reduces their effectiveness in managing schools. This is because the principal's work includes not only budgeting, scheduling, and other managerial work, but includes also hiring new teachers, providing teacher evaluations, and acting as a leader in developing the schools' educational objectives. Moreover, quality assurance is the responsiblity of the principals and other managers in the education administration outside the school. Education and certification processes for school administrators versus teachers have diverged, and this has resulted in two distinct school professions. Significant reforms have attempted to increase the integration of teachers, but the crucial need to promote the concept of teacher leadership indicates just how weakly institutionalized teachers' leadership roles are in the U.S. This means that teachers have not been able to assert control over and set standards for their own training and certification in the same way as, for example, the legal and medical professions have.

The Singaporean system is highly centralized. The system has invested a lot in teachers' professional development. Low, the author of the Singaporean case, emphasizes that teachers need a strong sense of the purpose of teaching and the identity of the teacher. Teachers who have a strong professional identity also uphold their roles as professionals and are driven to continually learn in order to be able to deliver high standards of teaching in the classroom. As professionals, teachers strive to update their knowledge and use this knowledge. Teachers' roles in Singapore are collectively determined by the Ministry of Education and the school leaders in line with the nation's articulated and desired outcomes of education. In the Singaporean case, it seems that teachers are supported in many ways in their work, which brings a positive viewpoint to centralized systems.

\section{THE CONCEPT OF SCHOOL IS CHANGING}

All the chapters from different countries claim there a huge change in teachers' work. They also describe tensions and their solutions involved in how teachers' professional role contribute to the educational systems. The 21 st century competencies are included in most countries' school curricula and they set high demands on teachers. The work is expanding from classrooms to wider contexts. The OECD's report (2009) on effective teaching recommends that it is useful to distinguish between teaching competences and teacher competences. Teaching competences are focused on the role of the teacher in the classroom and are directly linked with the 'craft' of teaching, including professional knowledge and skills mobilized for action (Hagger and McIntyre 2006). Teacher competencies imply a wider, systemic view of teacher professionalism on multiple levels, including the individual, the school, the local community and professional networks. For example Finland and Estonia are emphasising in their new teacher education strategies or curricula new types of competencies emphasising the teachers' role as creative designers of learning environments and competences which are needed in the collaborative development of school sites and operations. 
Based on an OECD Report (2001, p. 119), Lee and Tan describe scenarios for the role of schools in the future societies. The two scenarios of "de-schooling" and "re-schooling" can be identified already in many societies. The "de-schooling" scenario emerges through the "widespread establishment of non-formal learning networks, facilitated both by ICT and a 'network society' environment" (OECD, 2001, p. 119). On the one hand, there could be widespread dissatisfaction with the school systems from the public. On the other hand, the ubiquity of computers and the internet will allow students to access and share information freely. This scenario is in tune with the themes of the lifelong learning agenda, emphasizing flexibility and individualization. It stresses cooperation rather than competition. To a certain extent, this scenario is already visible society progresses towards the "network society. The "Re-schooling" category involves schools functioning beyond their traditional academic teaching role and assuming the role of social centres. There will be more of a partnership between schools and the community. The boundaries between formal and informal learning will become blurred, and there will be more emphasis on adopting lifelong learning skills.

These two scenarios radically change teachers' roles within and outside classrooms. The teacher's role may be really different depending on the educational system. Without professional autonomy and support, it would be very difficult to aim at objectives that are very open, wide, complex and emphasize processes instead of mere outcomes or products. Teachers need new methods and also new partnerships between teachers and other educational actors including administration. Isolated, undervalued teachers or teacher proof curricula will not work in the circumstances where $21 \mathrm{st}$ century skills and competencies are in focus. Teacher's professional work needs autonomy and support. It also requires that the viewpoints of teachers are taken into account when reforms are planned and teachers have opportunities to take leadership roles in their own work. This does not happen in isolation. The only ways to change educational conditions and structures are partnerships and interconnectedness within the teaching profession.

\section{TOWARDS EDUCATIONAL ECOSYSTEMS}

The ecosystem concept has recently been expanded to include more human contexts, especially social structures. A high level of interconnectedness and interdependence and the flow of information are the most important features of the ecosystem concept in biology. Human systems in the same way as natural environments, w can lose their functionality and resilience if some of the actors take control and exert their power and authority over others, and if communication only flows in one direction as it does in a top-down strategy. The system only functions well when all its different parts work together. Human ecosystems are led, intervened in and developed by humans and human actions. We must be aware of how different actors influence the system. We must identify the barriers and obstacles that should be overcome in order to make educational ecosystems functional. It requires that we identify, analyze and manage educational systems and their subsystems and understand what makes up the teachers' role in the systems. Teachers' work depends on macrolevel systems as well as institutional cultures, but they are also actors who influence those systems and processes.

We can learn from earlier studies (e.g. Walpole et al., 2016; Schwinda et al., 2016) that natural ecosystems that are impacted by human actions can have serious dysfunctions and imbalances, as we have learned from the many reports on climate change. The same is true for educational ecosystems. We can see that the partners and actors in these systems are often not interconnected. Many reports from different countries have highlighted the dire consequences systems if teachers are not heard and supported in their profession. We may ask how the systems can be developed to make teachers' work meaningful and respected. The work done by teachers is a huge resource in economies, and as they are allowed to work as real professionals they can make their best contributions to their students and society.

\section{REFERENCES}

Attard Tonna, M. \& Calleja, C. (2015). Teacher professional development and social networking: A case study of a professional learning experience. In C. Calleja, \& C. Johnston (Eds.). A learning paradigm: Informed knowledge of the learning self (pp. 101-118). Malta: Horizons.

Goe, L., Bell, C., \& Little, O. (2008). Approaches to evaluating teacher effectiveness: A research synthesis. Washington, DC: National Comprehensive Center for Teacher Quality.

Berger, N. \& Fisher, P. (2013). A well-educated workforce is key to state prosperity. Economic Analysis and Research Network (EARN). Washington: Economic Policy Institute. http://www.epi.org/publication/states-education-productivity-growth-foundations/

Borg, M., \& Bugeja, S. (2015). The management of change in a context of reform. Unpublished B.Ed. (Hons.) Dissertation, Faculty of Education, University of Malta, Malta.

Cutajar, M. (2015). An analysis of inter-school working in state-maintained colleges in the Maltese Islands. Unpublished PhD thesis presented at the Department of Education, University of Bath.

Gordon, S.P. (2004). Professional development for school improvement: Empowering learning communities. Boston, MA: Allyn \& Bacon.

Griffin, P., Care, B. \& McGaw, E. (2012). The changing role of education and schools. In P. Griffin, B. Care \& E. McGaw (Eds.) Assessment and teaching of 21st Century skills (pp. 1-15). Dodrecht: Springer.

Hagger, H., \& McIntyre, D. (2006). Learning teaching from teachers: realising the potential of school-based teacher education. Maidenhead: Open University Press.

Halinen, I. \& Jarvinen, R. (2008) Towards inclusive education: The Case of FINLAND. Prospects, 38, 77-97.

Helterbran, V.R. (2008). Professionalism: Teachers taking the reins. The Clearing House: A Journal of Educational Strategies, Issues and Ideas, Vol. 81(3): 123-127. 
Müller, J., Norrie, C., Hernández, F. \& Goodson, I. (2010). Restructuring teachers' work-lives and knowledge in England and Spain. Compare: A Journal of Comparative and International Education, 40(3), 265-277.

OECD (2001). Education policy analysis. Paris: OECD.

Portelli, V. (2004). Exploring teacher motivation, satisfaction and health in the secondary sector. Unpublished B.Ed. (Hons.) Dissertation, Faculty of Education, University of Malta, Malta.

Schwinda, J., Gilardia, K., Beasleyb, V., Mazeta, J., \& Smitha, W. (2016). Advancing the 'One Health' workforce by integrating ecosystem health practice into veterinary medical education: The Envirovet Summer Institute. Health Education Journal, 75(2), $170-183$.

Toom, A., Pietarinen, J., Soini, T. \& Pyhältö, K. (2017). How does the learning environment in teacher education cultivate first year student teachers' sense of professional agency in the professional community? Teaching and Teacher Education, 63, 126-136. DOI: 10.1016/j.tate.2016.12.013

Voogt, J. \& Roblin, N. P. (2012) A comparative analysis of international frameworks for 21 st century competences: Implications for national curriculum policies. Journal of Curriculum Studies, 44(3), 299-321. DOI: 10.1080/00220272.2012.668938

Walpole, S. C., Pearson, D., Coad, J., \& Barna, S. (2016). Medical Teacher, 38(4), 338-356.

\section{AFFILIATIONS}

\section{Hannele Niemi}

Faculty of Educational Sciences,

University of Helsinki, Finland

Auli Toom

Centre for University Teaching and Learning

Faculty of Educational Sciences,

University of Helsinki, Finland

Institute of Education, University of Tartu, Estonia

Arto Kallioniemi

Faculty of Educational Sciences,

University of Helsinki, Finland

Jari Lavonen

Faculty of Educational Sciences,

University of Helsinki, Finland 